\title{
Speciation of Dissolved Trace Nickel in Environmental Waters by On-Line Sonodigestion-Flow Injection Solid Phase Extraction Coupled to Flame Atomic Absorption Spectrometry
}

\author{
María Carmen Yebra-Biurrun $^{1 *}$, Jesús Manuel Castro-Romero ${ }^{2}$ \\ ${ }^{1}$ Department of Analytical Chemistry, Nutrition and Bromatology, Faculty of Chemistry, University of Santiago de \\ Compostela, Santiago de Compostela, Spain \\ ${ }^{2}$ Department of Analytical Chemistry, Escuela Universitaria Politécnica, University of A Coruña, Ferrol, Spain \\ E-mail:*mcarmen.yebra@usc.es \\ Received January 5, 2011; revised January 19, 2011; accepted January 20, 2011
}

\begin{abstract}
A simple on-line sonodigestion system was successfully used for breakdown organic nickel complexes in environmental waters acidified with diluted nitric acid prior to flow injection total dissolved nickel preconcentration in a microcolumn containing a chelating resin (Chelite Che with iminodiacetic acid groups) and determination by flame atomic absorption spectrometry. For the determination of the dissolved labile nickel fraction, microcolumns packed with the chelating resin were loaded in-situ with the sample without sample $\mathrm{pH}$ modification, and once in the laboratory were inserted in the flow injection device where nickel elution-detection was carried out. The performance of the chelating resin was investigated in order to elucidate its behavior in the presence of dissolved nickel species. The results obtained reveal that the resin, at the experimental employed conditions, retained only dissolved free nickel ions and nickel bound to weak complexes (labile fraction). The figures of merit for determinations in both nickel fractions are given and the obtained values are discussed. The speciation scheme is applied to the analysis of nickel in river and seawater samples collected in Galicia (Northwest, Spain). The results of fractionation showed that Ni are mainly in the dissolved labile fraction in river water, while in seawater samples analyzed was mainly present in the organic fraction.
\end{abstract}

Keywords: Sonodigestion, Preconcentration, Flow Injection, Nickel Speciation, Flame Atomic Absorption Spectrometry, Environmental Water

\section{Introduction}

Nickel is a transition metal element that is widespread in the natural environment, and fulfils an important role in many biochemical processes. Once dissolved in fresh or sea water, the form of aqueous nickel is influenced by $\mathrm{pH}$, redox conditions, ionic strength, the type and concentration of inorganic and organic ligands, pressure and temperature, and the surfaces available for adsorption $[1,2]$. Thus, speciation studies of nickel in natural aquatic environments such as rivers, lakes, estuaries and seas must distinguish between dissolved and particulate nickel. The aqueous solubility of nickel compounds and their chemical form and oxidation state in water strongly in- fluences their bioavailability and therefore toxicity. The dissolved nickel fraction in fresh and sea water forms free hydrated $\mathrm{Ni}(\mathrm{II})$ cations and soluble nickel inorganic and organic complexes of different stability [3]. An important group of complexing agents in natural waters, which forms very stable complexes with transition metals, is called the dissolved organic matter (DOM) [4]. Humic and fulvic substances, which are made up of a complex mixture of residues from the decomposition of plants and animals, are the main components of DOM in the aquatic environment, consisting of $30 \%-80 \%$ dissolved organic carbon in waters. Several studies have shown that binding of metallic ions with humic substances increases metal mobility in natural waters and 
controls their toxicity, bioavailability and transport $[5,6]$. Therefore, reliable measurements of nickel fractions are mandatory to study the behavior of this trace metal in environmental waters.

One of the approaches for species fractionation involves the use of chelating resins [7]. This operational procedure is based on the retention of free (aquo ions) and weakly complexed species (the labile fraction), while the inert metal fraction (formed by stable complexes formed between nickel and DOM) does not interact with the chelating groups of the resin and remaining in solution. For this, Chelex-100 resin containing chelating iminodiacetate groups is the resin most widely employed [8-10]. However, it is crucial to determine the $\mathrm{Ni}$ species present before and after all sampling and storage procedures to track any changes in species distribution [11]. The use of on-site sampling/preconcentration devices based on microcolumns is a simple alternative for this purpose because of its relative easy to develop and exploit automated manifolds, which allow change sampling conditions (such as water level or sample flowrate), filter and preconcentrate the sample. As a result, this methodology preserve the sample for further laboratory analysis, which can be easily carried out incorporating the sample loaded microcolumns into a flow injection manifold [12-15].

Regarding the determination of total dissolved trace metals concentration, the high concentration of alkali and alkaline earth metal ions, and the high saline matrix makes very difficult direct analysis of seawater even by the most sensitive analytical techniques [16]. Therefore, a separation/preconcentration step is frequently necessary in the analytical process. If the separation technique chosen involves chelation, it is required to release the trace metal from the metal-organic complex prior the application of the separation technique. Sample acidification could breakdown organic complexes, but as acidified samples must have their $\mathrm{pH}$ adjusted prior the separation step, metals can re-complex with the dissolved organic ligands to form again non-labile complexes. Therefore, an adequate degradation or digestion of organic ligands is mandatory [17]. In the last years, the removal of DOM is performed by ultraviolet radiation. Nevertheless, there is disagreement about experimental conditions applied for natural water digestion. Thus, water samples were acidified with hydrochloric acid or nitric (until pH about 1.7 to 2.2) with [18] and without $[19,20]$ the presence of diluted hydrogen peroxide, and UV digestion time ranged between 0.5 to $8 \mathrm{~h}$. By the other hand, flow injection procedures reduced this time to $5-9.3 \mathrm{~min}$ [21]. Development and application of sonolysis (ultrasound) is starting to gain an important place in this domain. Ultrasound can degrade metal organic complexes by means of oxidative reactions, which are increased by the presence of nitric acid because the hydrogen peroxide formed as a result of water sonolysis was found to be about twice that observed in pure water under identical sonochemical conditions [22,23]. As a result, this methodology is used for the treatment of wastewater containing organic compounds to decompose them into highly degradable products [24], for degradation of organomercurials to determine inorganic and total mercury [25] and in a continuous mode to digest urine samples [26] and for sonolysis of seawater samples [27].

The main objective of this work is to present an automatic flow injection (FI) system coupled to flame atomic absorption spectrometry (FAAS) for the determination of total dissolved and labile nickel species in environmental waters. The fractionation of labile and non-labile inert nickel species is based on a chelating resin because the Serdolit Chelite Che chelating resin (containing iminodiacetic acid groups) is suitable to preconcentrate/separate only free and labile forms of nickel. Prior to passing through the resin-containing microcolumn, samples were sonodigested on-line to decompose organic complexes and to allow for the determination of total dissolved Ni. This speciation scheme was applied to the analysis of river surface and sea water samples collected in Galicia (Northwest, Spain).

\section{Experimental}

\subsection{Instrumentation}

The on-line system used is shown in Figure 1. It consisted of two Gilson Minipuls 3 peristaltic pumps (Gilson, France), five Rheodyne low-pressure injection valves (four of them adapted to work as selection valves) (Rheodyne, USA), an ultrasonic bath (Selecta, Spain) and a digestion chamber (three glass minicolumns connected in series, $100 \mathrm{~mm} \times 15 \mathrm{~mm}$ i.d., bed volume $12 \mathrm{~mL}$, Omnifit, UK). The laboratory-made microcolumn for the on-line preconcentration step was prepared filling Viton tubes $(100 \mathrm{~mm} \times 1.1 \mathrm{~mm}$ i.d. $)$ with $50 \mathrm{mg}$ of Serdolit Chelite Che chelating resin. The experiments were performed with a Perkin Elmer Model 5000 (PerkinElmer Life and Analytical Sciences, USA) air-acetylene flame atomic absorption spectrometer attached to a Perkin Elmer Model 50 Servograph Recorder with a range of $5 \mathrm{mV}$. A Ni hollow cathode lamp, operated according to the manufacturer's recommendations, was utilized as a radiation source.

All glassware was decontaminated with $10 \%(\mathrm{v} / \mathrm{v}) \mathrm{ni}-$ tric acid for at least $48 \mathrm{~h}$ and washed three times with Milli-Q water before use. 


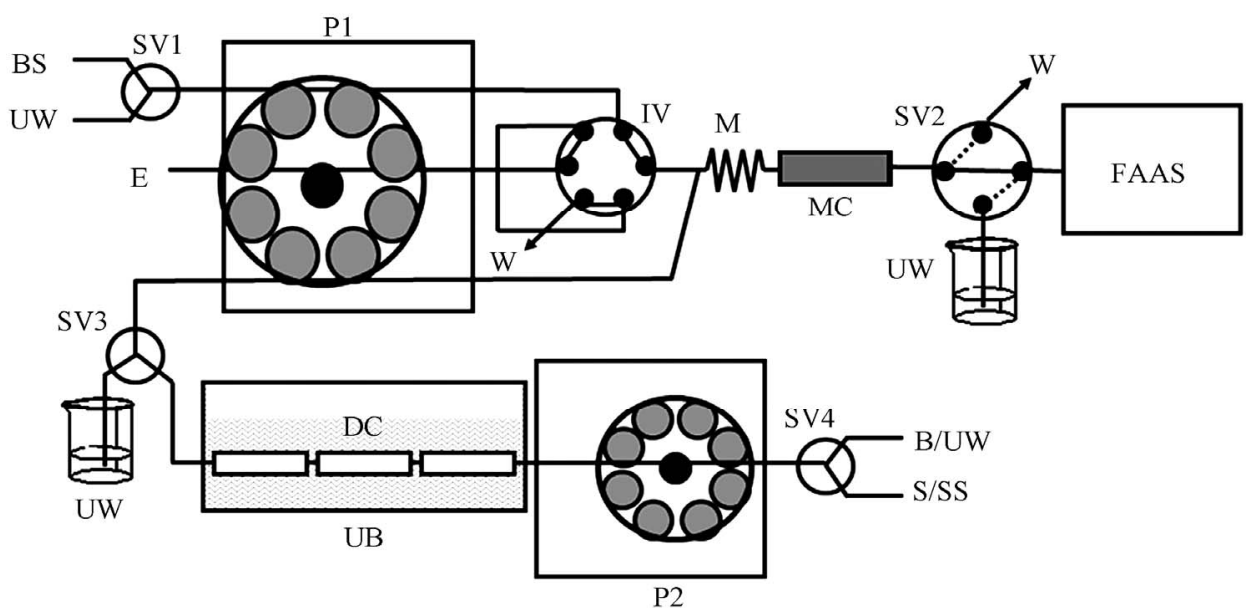

Figure 1. Schematic of the flow injection manifold used for the determination of total and labile dissolved Ni(II) in environmental water samples. B: blank; BS: buffer solution; DC: digestion chamber; E: eluent; FAAS: flame atomic absorption spectrometer; IV: injection valve; M: mixing coil; MC: microcolumn containing the resin Serdolit Chelite Che; P1 and P2: peristaltic pumps; S/SS: sample or standard solution; SV1, SV2, SV3 and SV4: selecting valves; UB: ultrasonic bath; UW: ultrapure water; $\mathrm{W}$ : waste.

\subsection{Reagents and Samples}

Nickel stock solution $\left(1000 \mu \mathrm{g} \cdot \mathrm{mL}^{-1}\right)$ was purchased from Merck (Germany). The nitric acid used to water acidification and the hydrochloric acid used to the elution step were from Merck (Germany). The chelating resin containing iminodiacetic acid groups was Serdolit Chelite Che (Serva Electrophoresis, Germany). Ammonia-ammonium chloride buffer solution $(\mathrm{pH} 8)$ was prepared by dissolution of $1.1 \mathrm{~g}$ of ammonium chloride (Merck, Germany) in $100 \mathrm{~mL}$ of ultrapure water and adjust the $\mathrm{pH}$ to 8.0 by adding diluted ammonia (Merck, Germany). Aqueous solutions of humic acid (SigmaAldrich, Switzerland), ethylenediaminetetraacetic acid (EDTA), sodium chloride and sodium sulfate (Merck, Germany) were prepared as model natural ligands. Certified reference material Slew-3 (estuarine water) obtained from the National Research Council of Canada. Solutions (reagents and standards) were prepared using ultrapure water of $18.2 \mathrm{M} \Omega \mathrm{cm}$ resistivity, obtained from a Milli-Q water purification system (Millipore, USA).

Statistical analysis of the experimental designs was carried out by means of the Statgraphics Plus V.5.1 statistical package (Manugistic, Inc., USA).

Surface river water and seawater samples were collected in Galicia (Northwest, Spain). For the determination of total dissolved nickel, samples were collected in pre-cleaned glass bottles, filtered through a $0.45 \mu \mathrm{m}$ membrane filter (mixed cellulose esters, Millipore Ibérica, Spain); and immediately acidified with $10 \mathrm{~mL}$ of concentrated nitric acid to avoid metal adsorption on the container walls. The samples were stored in a refrigerator $\left(4^{\circ} \mathrm{C}\right)$ for no longer than two weeks. For the determina- tion of the nickel labile fraction, water samples were preconcentrated on-site without prior $\mathrm{pH}$ modification. After on-line filtration with a $0.45 \mu \mathrm{m}$ filter, $200 \mathrm{~mL}$ of each sample was passed through a resin-containing microcolumn at a flow rate of $4.0 \mathrm{~mL} \cdot \mathrm{min}^{-1}$ [13]. As a result, nickel was retained on the microcolumn only in its labile fraction. After loading, the resin was washed with ultrapure water and the residual internal fluid drawn off. The microcolumns were transported in a portable refrigerator, and returned to the laboratory where they were stored in a refrigerator until further analysis.

\subsection{Procedure}

For the determination of the concentration of the nickel labile fraction, the in-situ loaded microcolumns were connected to the FI manifold shown in Figure 1. The microcolumn was located immediately before the detector. The analysis procedure consists of the injection of $110 \mu \mathrm{L}$ of $3 \mathrm{~mol} \cdot \mathrm{L}^{-1}$ hydrochloric acid into a carrier ultrapure water pumped at $5.0 \mathrm{~mL} \cdot \mathrm{min}^{-1}$. Thus, the labile fraction of nickel is released directly into the nebulizer of the FAAS spectrometer at a flow-rate of $5.0 \mathrm{~mL} \cdot \mathrm{min}^{-1}$.

The determination of the total dissolved concentration of nickel takes place after decomposition of metal organic complexes by sonodigestion. Thus, water samples $(30 \mathrm{~mL})$ in $0.6 \mathrm{~mol} \cdot \mathrm{L}^{-1}$ nitric acid medium are inserted into the flow system at $5.0 \mathrm{~mL} \cdot \mathrm{min}^{-1}$ by means of a peristaltic pump (P2). Once all the sample volume is located in the digestion chamber (three glass minicolumns connected in series (DC)), which are immersed within the ultrasonic bath at room temperature, the pump controlling the sample stream (P2) was stopped and the sample 
stays under the action of ultrasound energy for a period of $120 \mathrm{~s}$. After, the selecting valve (SV3) was switched to its other position to select the digestion chamber downstream, and the pump P2 was again activated. In this way, the sonodigested water sample arrives at the part of the FI system where the preconcentration step takes place, and converged with the buffer stream (ammonia-ammonium chloride buffer solution, $\mathrm{pH} 8$ ) in order to obtain the optimum $\mathrm{pH}$ value for metal retention in the chelating resin. Both channels are homogenized in the mixing coil and then, the resulting stream passed through the microcolumn containing the chelating resin (Serdolit Chelite Che). By means of SV2, the sample matrix is sent to waste, while ultrapure water flowing through the detector by the nebulizer suction. Finally, the retained nickel was subsequently eluted by injection of $110 \mu \mathrm{L}$ of $3 \mathrm{~mol} \cdot \mathrm{L}^{-1}$ hydrochloric acid into a water carried stream, being continuously monitored by a FAAS instrument. In order to avoid carry-over, a washing step was including in the analysis cycle. Thus, between each sample analysis, the digestion chamber was washed with ultrapure water during $60 \mathrm{~s}$. For this, the selecting valve (SV4) was switched to select the ultrapure water stream channel, while the wash water was sent to waste through SV3.

\section{Results and Discussion}

In this work, was chosen a resin with iminodiacetic acid groups (Serdolit Chelite Che) because a commercial resin containing this chelating group as Chelex-100 was proved to be an excellent medium for metal speciation. However, few reports appear in the bibliography in which other resins with these chelating groups are employed for speciation schemes [8,9]. Furthermore, the chelating resin Serdolit Chelite Che is a macroporous (macroreticular) polystyrene based resin, which effectively size excludes colloids from binding sites. Moreover, this resin has as advantage a wide $\mathrm{pH}$ range including unpolluted river and sea water [28]. Thus, the labile nickel fraction can be retained by the resin without $\mathrm{pH}$ modification, which prevent of changes in the analytical composition of the different nickel fractions.

\subsection{Effect of Complexing Agents}

Competition for metals from ligands in solution will determine the distribution among labile (free (aquo-ions) and weakly complexed species) and inert fractions (metal complexes unable to be dissociated by interaction with the active groups of the resin). In this study were selected as representative ligands chloride, sulfate, EDTA and humic acid at a concentration of 19000, 905, 30 and
$30 \mathrm{mg} \cdot \mathrm{L}^{-1}$, respectively. The inorganic ligands chosen are the major anionic components of river and sea water, and regarding the organic ligands, humic acids are the very important. EDTA is an organic ligand present in environmental waters, which is frequently used as organic ligand model because has high affinity for metals, with which forms strong complexes [29]. The influence of these ligands on the complexation and retention of nickel by the Serdolit Chelite Che resin was investigated at $\mathrm{pH} 6-8$ by using a solution containing $1 \mu \mathrm{g} \cdot \mathrm{L}^{-1}$ of $\mathrm{Ni}(\mathrm{II})$ and a volume of $200 \mathrm{~mL}$. The results of this study, shown in Figure 2, demonstrate that for both $\mathrm{pH}$ studied, more than $95 \% \mathrm{Ni}$ (II) in chloride and sulfate solutions were retained by the resin. It is due to the formation of labile complexes with these anions. Nevertheless, when the solution contains humic acid or EDTA, for both tested $\mathrm{pH}$ values the nickel recovery was less than $10 \%$. This behavior can be explained by the formation of nonlabile complexes, which are not retained on the chelating resin. Thus, in view of the obtained values, it was established that the Serdolite Chelite Che resin can be used for separation of the free and the labile nickel fraction from their inert complexes formed with organic ligands.

\subsection{Optimization of the Experimental Conditions for the FI Preconcentration of $\mathrm{Ni}(\mathrm{II})$}

Experimental work was initially focused on the optimization of the variables implied on the utilization of the chelating resin Serdolite Chelite Che in an on-line mode because the preconcentration step determines the efficiency of the final method. By applying the PlackettBurman statistical method, it was possible to select the variables which had the largest influence on percentage of nickel recovery (analytical response). The selected

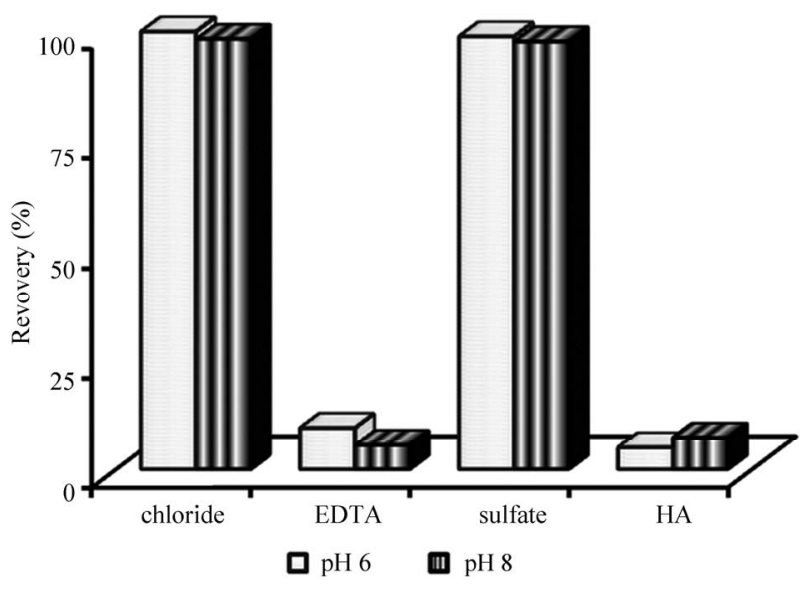

Figure 2. Influence of several ligands on the complexation and retention of $\mathrm{Ni}(\mathrm{II})$. 
factors and their levels are presented in Table 1. These factors were selected according to available data and experience gathered in previous screening experiments. Thus, a screening Plackett-Burman $2 \wedge 6 \times 3 / 16$ experimental design with one centerpoint, which studied the effects of the factors in 13 experiments was run. All experiments were performed using a sample volume of 30 $\mathrm{mL}$ and introducing a standard solution of $1 \mu \mathrm{g} \cdot \mathrm{L}^{-1}$ of Ni(II) into the FI manifold. The analysis of the results produced the main effect Pareto chart $(\mathrm{P}=95 \%)$ (Figure 3). In these charts, bar lengths are proportional to the absolute value of the estimated effect, which helps when comparing the relative importance of effects. The minimum " $t$ " value at the $95 \%$ confidence interval was 2.4 . The $t$ value is plotted as a vertical black line in Figure 3. We considered as significant any variable that offered a value higher than $\pm \mathrm{t}$. Pareto chart (Figure 3) shows the most important factors affecting the on-line preconcentration of nickel. The sample $\mathrm{pH}$ (A), the eluent concentration (diluted hydrochloric acid) (C) and the eluent volume (E) were statistically significant with positive sign. The sample flow-rate, (B) was a variable with a great influence on the experimental response with negative sign. The other variables considered, elution flowrate and minicolumn diameter did not produce any significant effect. Therefore, these statistically insignificant variables were fixed at certain values taking into account the best operational, flow and analytical conditions.
While the significant ones (sample $\mathrm{pH}$ (A), sample flow-rate (B), eluent concentration $(\mathrm{C})$ and eluent volume (E)) were optimized by using a central composite $2^{4}$ + star design with 11 error degree of freedom and 26 runs. Table 1 lists the upper and lower values given for each variable together with the fixed values for insignificant variables studied in the screening design. By use of the standardized Pareto chart is found that the sample $\mathrm{pH}$ and eluent concentration are statistically significant factors in the ranges under study. Thus, maximum values tested for these variables were selected as optimum. The values chosen for sample flow-rate and eluent volume were a compromise between reasonable recovery, reasonable analysis time, and adequate concentration factor achieved. The choice was inferred from predictions provided by the Statgraphics software. The values selected, on the basis of results obtained by use of the response surface (Figure 4), are listed in Table 1. As the recovery in the optimum conditions for $\mathrm{pH}$ values studied ranged between $85.7 \%$ to $96.7 \%$, it was verify the optimum $\mathrm{pH}$ range for nickel preconcentration. Thus, recovery was calculated under the selected experimental conditions and modifying the sample $\mathrm{pH}$ (between 4 and 8 ). The results obtained demonstrated that nickel was recovered quantitatively in the $\mathrm{pH}$ range $5-8$. This $\mathrm{pH}$ range includes the normal $\mathrm{pH}$ range of river and sea water, which implies that the $\mathrm{pH}$ does not have to be modified when the labile nickel species are on-site preconcentrated.

Table 1. Variables and their experimental levels adopted for the selection of variables involving the FI preconcentration step.

\begin{tabular}{|c|c|c|c|c|c|c|c|}
\hline \multirow{3}{*}{ Variable } & \multicolumn{4}{|c|}{ Plackett-Burman $2^{\wedge} 6 \times 3 / 16$ design } & \multicolumn{3}{|c|}{$2^{\wedge} 4+$ star central composite design } \\
\hline & \multirow{2}{*}{ Key } & \multicolumn{2}{|c|}{ Level } & \multirow{2}{*}{ Optimum } & \multicolumn{2}{|c|}{ Level } & \multirow{2}{*}{ Optimum } \\
\hline & & Low & Upper & & Low & Upper & \\
\hline Sample pH & A & 1 & 8 & - & 2 & 8 & 8 \\
\hline Sample flow-rate $\left(\mathrm{mL} \cdot \mathrm{min}^{-1}\right)$ & B & 1 & 5 & - & 1 & 4 & 4 \\
\hline $\mathrm{HCl}$ concentration (eluent solution, $\mathrm{mol} \cdot \mathrm{L}^{-1}$ ) & $\mathrm{C}$ & 0.1 & 3 & - & 1 & 3 & 3 \\
\hline Elution flow-rate $\left(\mathrm{mL} \cdot \mathrm{min}^{-1}\right)$ & $\mathrm{D}$ & 3 & 5 & 5 & - & - & - \\
\hline Eluent volume $(\mu \mathrm{L})$ & $\mathrm{E}$ & 70 & 110 & - & 90 & 110 & 110 \\
\hline Minicolumn diameter (mm) & $\mathrm{F}$ & 1.1 & 2.3 & 1.1 & - & - & - \\
\hline
\end{tabular}

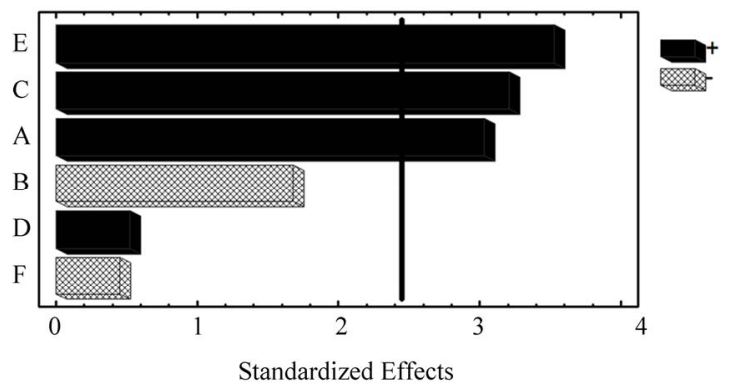

Figure 3. Pareto chart for the Plackett-Burman design applied to optimize the FI preconcentration step.

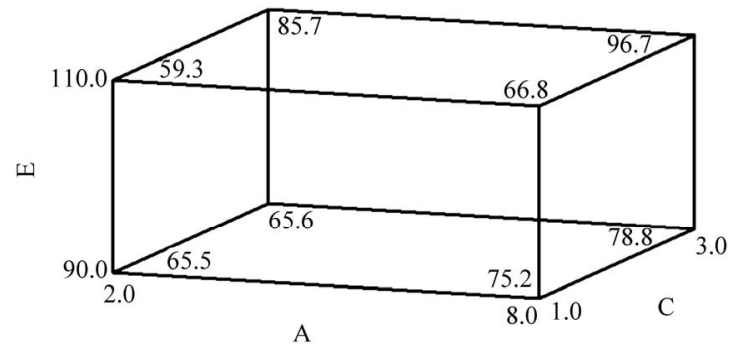

Figure 4. Cubic response surface estimated for the central composite design in the optimization of the FI preconcentration step. 


\subsection{Optimization of the Experimental Conditions for the On-Line Sonodigestion of Environmental Water Samples}

The optimization of the variables affecting the on-line sonodigestion procedure of environmental water samples: concentration of nitric acid (acid sample medium) (A), sonication time (B) and sonodigestion temperature (C), was carried out by building a central composite design $\left(2^{3}+\right.$ star with 11 error degree of freedom, 16 randomized experiments and three replicates). The tested values for each variable are shown in Table 2. The response variable was the recovery calculated according to the following equation: $\% \mathrm{R}=(\mathrm{C} 1 / \mathrm{C} 2) \times 100$, where $\mathrm{C} 1$ is the concentration of $\mathrm{Ni}(\mathrm{II})$ obtained by the proposed procedure and $\mathrm{C} 2$ is the concentration obtained for the same water sample, but performing the sample digestion procedure by traditional way using ammonium peroxydisulfate at elevated temperature [30]. The experiments were performing by using a sample volume of $30 \mathrm{~mL}$, and as digestion chamber two possible operational modes were studied: 1) a glass minicolumn $(100 \mathrm{~mm} \times 25 \mathrm{~mm}$ i.d., bed volume $35 \mathrm{~mL}$ ), 2) three glass minicolumns connected in series $(100 \mathrm{~mm} \times 15 \mathrm{~mm}$ i.d., bed volume $12 \mathrm{~mL}$ ). After performing the experiments, it is proven that for both operational modes tested, sonodigestion temperature is not a significant variable, resulting in low estimated effects. In fact, some experiments result in quantitative recoveries when the sonodigestion tempera- ture is $20^{\circ} \mathrm{C}$. Therefore, $20^{\circ} \mathrm{C}$ (room temperature) was the value chosen as optimum for this variable. Thus, only the two statistically significant factors (with positive sign): acid sample medium concentration (A) and sonication time (B) were taken into account to analyze the design. The values chosen for these variables were a compromise between, reasonable analysis time and the lowest nitric acid concentration with which a quantitative recovery is obtained. The choice was inferred from predictions provided by the Statgraphics software. The values selected, on the basis of results obtained by use of the response surface (Figure 5) are listed in Table 2. The analysis of the response surface plot indicates that for the same sonodigestion acid medium $\left(0.6 \mathrm{~mol} \cdot \mathrm{L}^{-1}\right.$ nitric acid), the sonication time required for quantitative recovery when a single minicolumn was used as digestion chamber is higher than that need when three minicolumns were used. This can be explained by the fact that the single minicolumn has a diameter $(25 \mathrm{~mm})$ higher than that of the three minicolumns connected in series $(15 \mathrm{~mm})$, which generates a high attenuation of ultrasound waves, reducing the effects of ultrasound energy in the sample within the minicolumn. Consequently, in order to increase the analysis time, for subsequent work we decided to use minicolumns with the minor diameter $(15 \mathrm{~mm})$. As each column has a bed volume of $12 \mathrm{~mL}$, are necessary three to contain a water sample volume of $30 \mathrm{~mL}$. In these conditions, nickel was quantitatively recovered when the sonication time was $120 \mathrm{~s}$.

Table 2. Optimization of experimental parameters for continuous sonodigestion.

\begin{tabular}{lccccc}
\hline \multirow{2}{*}{ Variable } & \multicolumn{3}{c}{$2^{\wedge} 3+$ star central composite design } \\
\cline { 2 - 6 } & Key & \multicolumn{2}{c}{ Level } & \multicolumn{2}{c}{ Optimum } \\
\cline { 3 - 7 } & & Low & Upper & M1a & M2b \\
\hline Concentration of acid sample medium $\left(\right.$ nitric acid, $\left.\mathrm{mol} \cdot \mathrm{L}^{-1}\right)$ & $\mathrm{A}$ & 0.2 & 1 & 0.6 & 0.6 \\
Sonication time (min) & $\mathrm{B}$ & 60 & 240 & 180 & 120 \\
Sonodigestion temperature $\left({ }^{\circ} \mathrm{C}\right)$ & $\mathrm{C}$ & 20 & 50 & 20 & 20 \\
\hline
\end{tabular}

${ }^{a} \mathrm{M} 1$ : a glass minicolumn $(100 \mathrm{~mm} \times 25 \mathrm{~mm}$ i.d., bed volume $35 \mathrm{~mL}) ;{ }^{\mathrm{b}} \mathrm{M} 2$ : three glass minicolumns connected in series $(100 \mathrm{~mm} \times 15 \mathrm{~mm}$ i.d., bed volume $12 \mathrm{~mL})$. Total bed volume $36 \mathrm{~mL}$.

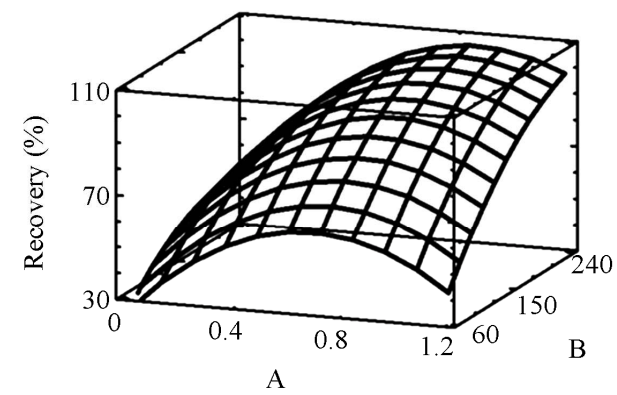

(a)

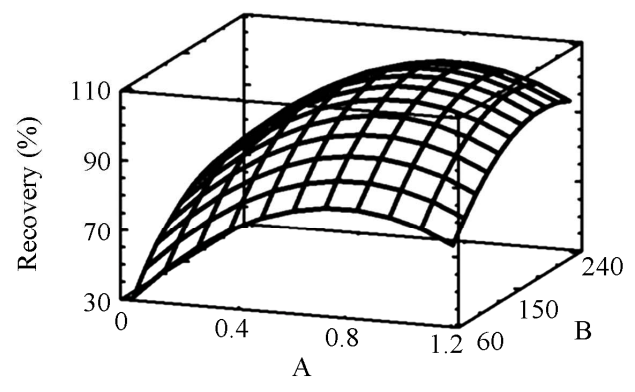

(b)

Figure 5. Response surfaces estimated for the central composite design in the optimization of the on-line sonodigestion. (a) Digestion chamber: one minicolumn (25 mm i.d.); (b) Digestion chamber: three minicolumns connected in series (15 mm i.d). 


\subsection{Analytical Data and Validation of the Method}

The sample volume used for the determination of the total dissolved concentration of nickel was $30 \mathrm{~mL}$, and the sample volume used for the determination of the dissolved labile nickel fraction was $200 \mathrm{~mL}$. Therefore, for each one of these sample volumes calibration plots were established by use standard solutions at eight concentrations levels $\left(0-7.5 \mu \mathrm{g} \cdot \mathrm{L}^{-1} \mathrm{Ni}\right.$ and $0-1.1 \mu \mathrm{g} \cdot \mathrm{L}^{-1} \mathrm{Ni}$, for 30 and $200 \mathrm{~mL}$, respectively). These standard solutions were treated in accordance with the sample-treatment procedure using the described optimized system described above.

The regression equations of the calibration graph obtained for both sample volumes are shown in Table 3. The limits of detection (LOD) and the limits of quantification (LOQ) for the different nickel fractions were calculated by use of the IUPAC criterion [31]. As a result of use a minor sample volume, the detection limit for the determination of the dissolved labile nickel fraction is lower than that for the determination of its total dissolved concentration.

Analytical and statistical data for each nickel fractions are summarized in Table 3 . The precision of the method (within day), expressed as relative standard deviation, was evaluated by eleven independent measurements of a water sample. The preconcentration factors calculated as the ratio of the slope of the calibration graph with and without preconcentration were also shown in Table 3. Analytical recovery was assessed after spiking aliquots of seawater and river water samples with metals (Table 3). It can be concluded that a complete analytical recovery (within the 95.5\% - 98.6\% range) was reached for both nickel fractions. A certified reference material (Slew-3) with a certificate value of $(1.23 \pm 0.07) \mu \mathrm{g} \cdot \mathrm{L}^{-1} \mathrm{Ni}$ was used to verify the accuracy of the proposed methodology.
The concentrations found was $(1.25 \pm 0.07) \mu \mathrm{g} \cdot \mathrm{L}^{-1}$, which is in concordance with the certified value. To evaluate the possible sample matrix interferences in the nickel determination, a standard addition method was performed. In this way, the certified reference material (Slew-3) was spiked with several nickel standard solutions $\left(0-5 \mu \mathrm{g} \cdot \mathrm{L}^{-1}\right)$. In these conditions, an addition calibration graph was run $(n=6)$ under the optimal chemical and flow conditions for the whole process. The equation was: absorbance $=8.8 \times 10^{-3} \mathrm{C}+0.011\left(\mathrm{r}^{2}=0.9996\right)$, where $\mathrm{C}$ is Ni concentration, expressed as $\mu \mathrm{g} \cdot \mathrm{L}^{-1}$. This equation and the calibration graph have the same slope, demonstrating that $\mathrm{Ni}$ determination is free of matrix interferences.

With the aim to establish the time that, once in situ loaded with water samples, the minicolumns could be stored before nickel determination, stability studies at optimum conditions were performed. For this, the nickel retained on minicolumns was determined at the same day of the sampling, and after 5 and 10 days stored at $4{ }^{\circ} \mathrm{C}$ (refrigerator). The obtained results indicated that minicolumns were stable for at least 10 days and could be stored during this time without any significant losses.

\subsection{Determination of Labile and Total Nickel in Environmental Water Samples}

In order to evaluate the analytical applicability of the proposed method, it was applied to the determination of labile and total nickel in several environmental water samples from Galicia (north-western Spain) and the results obtained are summarized in Table 4 (mean \pm standard deviation, $\mathrm{n}=3$ ). The percentages for the labile fraction of each metal are also presented in Table 4. Thus, it has demonstrated that in the analyzed seawater samples, nickel is principally present in the inert fraction forming strong organic complexes $((10.8 \pm 0.4) \%)$ in the

Table 3. Analytical and statistical data of the determination of total and labile dissolved nickel in environmental water samples.

\begin{tabular}{|c|c|c|}
\hline & Labile $\mathrm{Ni}$ & Total Ni \\
\hline Sample volume, $\mathrm{mL}$ & 200 & 30 \\
\hline Calibration equation $\left(\mathrm{C}, \mu \mathrm{g} \cdot \mathrm{L}^{-1}\right)$ & $5.9 \times 10^{-2} \mathrm{C}+8.0 \times 10^{-5}$ & $8.8 \times 10^{-3} \mathrm{C}+3.1 \times 10^{-4}$ \\
\hline Linear range, $\mu \mathrm{g} \cdot \mathrm{L}^{-1}$ & $0.065-1.17$ & $0.45-7.52$ \\
\hline Correlation coefficient, $\mathrm{r}^{2}$ & 0.999 & 0.999 \\
\hline Preconcentration factor & 1792.7 & 265.9 \\
\hline Detection limit, $\mu \mathrm{g} \cdot \mathrm{L}^{-1}$ & 0.021 & 0.13 \\
\hline $\operatorname{Recovery}(\%)^{\mathrm{a}}$ & 95.5 & 96.6 \\
\hline Recovery $(\%)^{b}$ & 96.9 & 98.5 \\
\hline $\operatorname{Recovery}(\%)^{\mathrm{c}}$ & 97.4 & 97.2 \\
\hline $\operatorname{Recovery}(\%)^{\mathrm{d}}$ & 98.6 & 97.7 \\
\hline
\end{tabular}

${ }^{\mathrm{a}}$ Total dissolved Ni: seawater sample spiked with $2 \mu \mathrm{g} \cdot \mathrm{L}^{-1}$. Labile dissolved Ni: seawater sample spiked with $0.3 \mu \mathrm{g} \cdot \mathrm{L}^{-1}$ (n $=3$ ); ${ }^{\mathrm{b}} \mathrm{Total}$ dissolved Ni: seawater sample spiked with $3 \mu \mathrm{g} \cdot \mathrm{L}^{-1}$. Labile dissolved Ni: seawater sample spiked with $0.4 \mu \mathrm{g} \cdot \mathrm{L}^{-1}(\mathrm{n}=3)$; ${ }^{\mathrm{c}}$ Total dissolved Ni: river water sample spiked with $3 \mu \mathrm{g} \cdot \mathrm{L}^{-1}$. Labile dissolved Ni: river water sample spiked with $0.3 \mu \mathrm{g} \cdot \mathrm{L}^{-1}(\mathrm{n}=3)$; ${ }^{\mathrm{d}}$ Total dissolved Ni: river water sample spiked with $5 \mu \mathrm{g} \cdot \mathrm{L}^{-1}$. Labile dissolved Ni: river water sample spiked with $0.5 \mu \mathrm{g} \cdot \mathrm{L}^{-1}(\mathrm{n}=3)$. 
Table 4. Determination of labile and total nickel in environmental water samples from Galicia (north-western Spain).

\begin{tabular}{|c|c|c|c|}
\hline \multirow[b]{2}{*}{ Sample } & \multicolumn{2}{|c|}{ Nickel concentration, $\mu \mathrm{g} \cdot \mathrm{L}^{-1}$} & \multirow[b]{2}{*}{$\% \mathrm{LF}^{\mathrm{a}}$} \\
\hline & Labile & Total & \\
\hline Seawater 1 & $0.48 \pm 0.02$ & $4.62 \pm 0.11$ & 10.4 \\
\hline Seawater 2 & $0.34 \pm 0.02$ & $3.22 \pm 0.17$ & 10.6 \\
\hline Seawater 3 & $0.19 \pm 0.01$ & $1.71 \pm 0.07$ & 11.1 \\
\hline Seawater 4 & $0.11 \pm 0.01$ & $1.03 \pm 0.07$ & 10.7 \\
\hline Seawater 5 & $0.26 \pm 0.02$ & $2.24 \pm 0.11$ & 11.6 \\
\hline Seawater 6 & $0.21 \pm 0.01$ & $1.97 \pm 0.07$ & 10.7 \\
\hline Seawater 7 & $0.42 \pm 0.02$ & $3.83 \pm 0.11$ & 11.0 \\
\hline Seawater 8 & $0.50 \pm 0.03$ & $4.55 \pm 0.07$ & 11.0 \\
\hline Seawater 9 & $0.63 \pm 0.03$ & $6.02 \pm 0.17$ & 10.5 \\
\hline Seawater 10 & $0.34 \pm 0.02$ & $3.26 \pm 0.23$ & 10.4 \\
\hline River water 1 & $1.15 \pm 0.01$ & $1.29 \pm 0.10$ & 89.1 \\
\hline River water 2 & $0.62 \pm 0.01$ & $0.68 \pm 0.03$ & 91.2 \\
\hline River water 3 & $1.06 \pm 0.01$ & $1.18 \pm 0.07$ & 89.8 \\
\hline River water 4 & $0.55 \pm 0.02$ & $0.61 \pm 0.03$ & 90.2 \\
\hline River water 5 & $0.82 \pm 0.01$ & $0.91 \pm 0.07$ & 90.1 \\
\hline River water 6 & $0.99 \pm 0.02$ & $1.14 \pm 0.09$ & 86.8 \\
\hline River water 7 & $0.90 \pm 0.01$ & $1.03 \pm 0.07$ & 87.4 \\
\hline River water 8 & $0.81 \pm 0.02$ & $0.96 \pm 0.03$ & 84.4 \\
\hline
\end{tabular}

${ }^{\mathrm{a}}$ LF: Percentage of labile fraction

labile dissolved fraction). By the other hand, in river water samples nickel is found mainly in the labile dissolved fraction $((88.6 \pm 2.3) \%)$.

\section{Conclusions}

A combination of continuous sonodigestion and solidphase extraction by using a chelating resin was exploited for dissolved nickel speciation in environmental water samples, determining labile (comprising the free ion, inorganic complexes and weak organic complexes) and total dissolved nickel (mainly comprising, additionally, strong organic complexes) with a high sensitivity and precision. Sonodigestion has been used for first time for decomposition of organic complexes of nickel from environmental waters, which allowed simplify sample preparation and speed up and the analysis time for the determination of total dissolved $\mathrm{Ni}$ concentration. On the other hand, for the determination of the labile fraction, it is demonstrated for the first time that Chelite Che resin can be used as an effective material for the in-situ separation/preconcentration of free and labile dissolved Ni(II) species. Furthermore, the proposed methodology could be applied with detection by inductively coupled plasma atomic emission spectrometry and inductively coupled plasma-mass spectrometry to improve analytical sensitivity.

\section{Acknowledgements}

This work has been funded by the Spain's Ministry of Science and Innovation, within the framework of Project CTQ 2009-12282.

\section{References}

[1] R. Mandal, N. M. Hassan, J. Murimboh, C. L. Chakrabarti and M. H. Back, "Chemical Speciation and Toxicity of Nickel Species in Natural Waters from the Sudbury Area (Canada)," Environmental Science and Technology, Vol. 36, No. 7, 2002, pp. 1477-1484. doi:10.1021/es015622e

[2] R. Cornellis, J. Caruso, H. Crews and K. Heumann, "Handbook of Elemental Speciation II: Species in the Environment, Food, Medicine and Occupational Health," 
John Wiley \& Sons Ltd., Chichester, 2005.

[3] M. Martino, A. Turner and M. Nimmo, "Distribution, Speciation and Particle-Water Interactions of Nickel in the Mersey Estuary, UK," Marine Chemistry, Vol. 88, No. 3-4, 2004, pp.161-177. doi:10.1016/j.marchem.2004.03.007

[4] J. D. Thomas, "The Role of Dissolved Organic Matter, Particularly Free Amino Acids and Humic Substances, in Freshwater Ecosystems," Freshwater Biology, Vol. 38, No. 1, 1997, pp. 1-36. doi:10.1046/j.1365-2427.1997.00206.x

[5] L. E. Doig and K. Liber, "Nickel Speciation in the Presence of Different Sources and Fractions of Dissolved Organic Matter," Ecotoxicology and Environmental Safety, Vol. 66, No. 2, 2007, pp. 169-177. doi:10.1016/j.ecoenv.2005.12.011

[6] I. V. Slaveykova, I. B. Karadjova, M. Karadjov and D. L. Tsalev, "Trace Metal Speciation and Bioavailability in Surface Waters of the Black Sea Coastal Area Avaluated by HF-PLM and DGT," Environmental Science and Technology, Vol. 43, No. 6, 2009, pp. 1798-1803. doi:10.1021/es $802544 \mathrm{n}$

[7] M. Pesavento, G. Alberti and R. Biesuz, "Analytical Methods for Determination of Free Metal Ion Concentration, Labile Species Fraction and Metal Complexation Capacity of Environmental Waters: A Review," Analytica Chimica Acta, Vol. 631, No. 2, 2009, pp. 129-141. doi:10.1016/j.aca.2008.10.046

[8] M. B. Alvarez, M. E. Malla and D. E. D. Batistoni, "Performance Evaluation of Two Chelating Ion-Exchange Sorbents for the Fractionation of Labile and Inert Metal Species from Aquatic Media," Analytical and Bioanalytical Chemistry, Vol. 378, No. 2, 2004, pp. 438-446. doi:10.1007/s00216-003-2237-y

[9] K. C. Bowles, S. C. Apte, G. E. Batley, L. H. Hales and N. J. Rogers, "A Rapid Chelex Column Method for the Determination of Metal Speciation in Natural Waters," Analytica Chimica Acta, Vol. 558, No. 1-2, 2006, pp. 237-245. doi:10.1016/j.aca.2005.10.071

[10] G. Alberti, R. Biesuz and M. Pesavento, "Determination of the Total Concentration and Speciation of Metal Ions in River, Estuarine and Seawater Samples," Analytical Sciences, Vol. 24, No. 12, 2008, pp. 1605-1611. doi:10.2116/analsci.24.1605

[11] D. L. Giokas, J. Antelo, E. K. Paleologos, F. Arce and M. I. Karayannis, "Copper Fractionation with Dissolved Organic Matter in Natural Waters and Wastewaters-A Mixed Micelle Mediated Methodology (Cloud Point Extraction) Employing Flame Atomic Absorption Spectrometry," Journal of Environmental Monitoring, Vol. 4, No. 4, 2002, pp. 505-510. doi:10.1039/b202668f

[12] G. M. Sawula, "On-Site Preconcentration and Trace Metal Ions Determination in the Okavango Delta Water System, Botswana," Talanta, Vol. 64, No. 1, 2004, pp. 80-86. doi:10.1016/j.talanta.2003.11.048

[13] M. C. Yebra-Biurrun, A. Moreno-Cid and L. Puig, "Minicolumn Field Preconcentration and Flow-Injection Flame Atomic Absorption Spectrometric Determination of Cadmium in Seawater," Analytica Chimica Acta, Vol. 524, No. 1-2, 2004, pp. 73-77. doi:10.1016/j.aca.2004.05.052

[14] K. Zih-Perényi and A. Lásztity, "On-Site Classification of Manganese Forms in Natural Waters by Membrane Filtration and Chelating Exchange," Spectrochimica Acta B, Vol. 60, No. 3, 2005, pp. 385-392. doi:10.1016/i.sab.2005.01.009

[15] J. P. Lafleur and E. D. Salin, "Pre-Concentration of Trace Metals on Centrifugal Microfluidic Discs with Direct Determination by Laser Ablation Inductively Coupled Plasma Mass Spectrometry," Journal of Analytical Atomic Spectrometry, Vol. 24, No. 11, 2009, pp. 1511-1516. doi: $10.1039 / \mathrm{b} 910276 \mathrm{k}$

[16] F. C. Domínguez-Lledó, M. D. Galindo-Riaño, I. C. Díaz-López, M. García-Vargas and M. D. Granado-Castro, "Applicability of a Liquid Membrane in Enrichment and Determination of Nickel Traces from Natural Waters," Analytical and Bioanalytical Chemistry, Vol. 389, No. 2, 2007, pp. 653-659. doi:10.1007/s00216-007-1472-z

[17] A. Limbeck, "Microwave-Assisted UV-Digestion Procedure for the Accurate Determination of Pd in Natural Waters," Analytica Chimica Acta, Vol. 575, No. 1, 2006, pp. 114-119. doi:10.1016/j.aca.2006.05.062

[18] E. P. Achterberg, C. B. Braungardt, R. C. Sandford and P. J. Worsfold, "UV Digestion of Seawater Samples Prior to the Determination of Copper Using Flow Injection with Chemiluminescence Detection," Analytica Chimica Acta, Vol. 440, No. 1, 2001, pp. 27-36.

doi:10.1016/S0003-2670(01)00824-8

[19] M. T. S. D. Vasconcelos and M. F. C. Leal, "Speciation of $\mathrm{Cu}, \mathrm{Pb}, \mathrm{Cd}$ and $\mathrm{Hg}$ in Waters of the Oporto Coast in Portugal, Using Pre-Concentration in a Chelamine Resin Column," Analytica Chimica Acta, Vol. 353, No. 2-3, 1997, pp. 189-198. doi:10.1016/S0003-2670(97)87777-X

[20] N. Ndung'u, R. P. Franks, K. W. Bruland and A. R. Flegal, "Organic Complexation and Total Dissolved Trace metal Analysis in Estuarine Waters: Comparison of Solvent-Extraction Graphite Furnace Atomic Absorption Spectrometric and Chelating Resin Flow Injection Inductively Coupled Plasma-Mass Spectrometric Analysis," Analytica Chimica Acta, Vol. 481, No. 1, 2003, pp. 127-138. doi:10.1016/S0003-2670(03)00063-1

[21] D. Point, G. Bareille, H. Pinaly, C. Belin and O. F. X. Donard, "Multielemental Speciation of Trace Elements in Estuarine Waters with Automated On-Site UV Photolysis and Resin Chelation Coupled to Inductively Coupled Plasma Mass Spectrometry," Talanta, Vol. 72, No. 3, 2007, pp. 1207-1216. doi:10.1016/j.talanta.2007.01.014

[22] L. Venault, Ph. Moisy, S. I. Nikitenko and C. Madic, "Kinetics of Nitrous Acid Formation in Nitric Acid Solutions under the Effect of Power Ultrasound," Ultrasonics Sonochemistry, Vol. 4. No. 2, 1997, pp. 195-204. doi:10.1016/S1350-4177(97)00010-2

[23] S. I. Nikitenko, L. Venault and Ph. Moisy, "Scavenging of $\mathrm{OH}$ Radicals Produced from $\mathrm{H}_{2} \mathrm{O}$ Sonolysis with Ni- 
trate Ions," Ultrasonics Sonochemistry, Vol. 11, No. 3-4, 2004, pp. 139-142. doi:10.1016/j.ultsonch.2004.01.009

[24] J. Madhavan, F. Grieser and M. Ashokkumar, "Degradation of Orange-G by Advanced Oxidation Processes," Ultrasonics Sonochemistry, Vol. 17, No. 2, 2010, pp. 338-343. doi:10.1016/j.ultsonch.2009.10.008

[25] J. L. Capelo, I. Lavilla and C. Bendicho, "Room Temperature Sonolysis-Based Advanced Oxidation Process for Degradation of Organomercurials: Application To Determination Of Inorganic And Total Mercury In Waters By Flow Injection-Cold Vapor Atomic Absorption Spectrometry," Analytical Chemistry, Vol. 72, No. 20, 2000, pp. 4979-4984. doi:10.1021/ac000470b

[26] R. M. Cespón-Romero and M. C. Yebra-Biurrun, "Determination of Trace Metals in Urine with an On-Line Ultrasound-Assisted Digestion System Combined with a Flow-Injection Preconcentration Manifold Coupled to Flame Atomic Absorption Spectrometry," Analytica Chimica Acta, Vol. 609, No. 2, 2008, pp. 184-191. doi:10.1016/j.aca.2008.01.002

[27] M. C. Yebra-Biurrun and N. Carro-Mariño, "Flow Injection Flame Atomic Absorption Determination of $\mathrm{Cu}, \mathrm{Mn}$ and Zn Partitioning in Seawater by On-Line Room Temperature Sonolysis and Minicolumn Chelating Resin Methodology," Talanta, Vol. 83, No. 2, 2010, pp. 425-430. doi:10.1016/j.talanta.2010.09.045

[28] E. R. Weiner, "Applications of Environmental Aquatic Chemistry: A Practical Guide," 2nd Edition, CRC Press, Boca Raton, 2008. doi:10.1201/9781420008371

[29] J. Hur, M. A. Schlautman and S. Yim, "Effects of Organic Ligands and $\mathrm{pH}$ on the Leaching of Copper from Brake Wear Debris in Model Environmental Solutions," Journal of Environmental Monitoring, Vol. 6, No. 1, 2004, pp. 89-94. doi:10.1039/b310125h

[30] M. C. Yebra-Biurrun, A. Bermejo-Barrera, M. L. Mella-Louzao and M. P. Bermejo-Barrera, "Determination of Copper Traces in Water by Atomic Absorption Spectrometry," Quimica Analitica, Vol. 10, No. 1, 1991, pp. 59-64.

[31] L. A. Currie, "Nomenclature in Evaluation of Analytical Methods Including Detection and Quantification Capabilities (IUPAC Recommendations 1995)," Analytica Chimica Acta, Vol. 391, No. 2, 1999, pp. 105-126. doi:10.1016/S0003-2670(99)00104-X 